\title{
Regression analysis of visual field progression in low tension glaucoma
}

\author{
B N Noureddin, D Poinoosawmy, F W Fietzke, R A Hitchings
}

\begin{abstract}
Eighty four patients (168 eyes) with low tension glaucoma were retrospectively reviewed (mean follow-up was 28 months). The mean age was 66 years, and $69 \%$ were females. Regression analysis of their automated Humphrey fields (a mean of eight fields per eye) showed progression in $\mathbf{5 0 \%}$ of patients and in $37 \%$ of eyes. There was no statistically significant difference between patients with progression and non-progression with respect to age $(p<0.5)$ or intraocular pressure $(p<0.5)$. Visual field defects were located most frequently in the superior hemifield in both groups of patients. A considerable proportion of patients had advanced field loss at the time of diagnosis.
\end{abstract}

Low tension glaucoma (LTG) has always been an intriguing form of optic neuropathy. As early as 1857 von Graefe ${ }^{1}$ noted disc cupping and pallor in some eyes in the presence of normal intraocular pressure. Since then the characteristics and details of visual field defects in LTG have been studied ${ }^{23}$ and frequently matched and compared to those in high pressure glaucoma. ${ }^{4-8}$ Despite this there is little evidence of the natural history of field loss in LTG. In earlier studies the number of patients and fields was relatively small. Chumbley and Brubaker' reported progression in $41 \%$ of 34 eyes ( 17 patients). Levene ${ }^{10}$ found the same proportion in his extensive review of 34 eyes in 23 patients. Anderton et al ${ }^{11}$ also observed $40 \%$ of 56 patients worsening when followed up for a mean of 10.5 years. Glicklich $e t$ $a l^{12}$ were the first to use automated perimetry to study progression in LTG. Their figure was 53\% at three years and $62 \%$ at five years follow-up. All his 36 patients were on medical treatment and $65 \%$ had a surgical procedure. His analysis was made on only three fields per eye.

We retrospectively reviewed patients with LTG followed up at Moorfields Eye Hospital. Regression analysis of automated fields was performed to determine the proportion of eyes which showed definite progression.

Moorfields Eye Hospital, Glaucoma Unit B N Noureddin D Poinoosawmy R A Hitchings

Department of Visual Science, Institute of Ophthalmology F W Fietzke

Correspondence to:

R A Hitchings, Moorfields Eye R A Hitchings, Moorfields Ey
Hospital, City Road, London EClV 2PD.

Accepted for publication

17 January 1991

Patients and methods

Patients with LTG followed up in the Glaucoma Unit at Moorfields Eye Hospital were retrospectively looked at for the purpose of our study. Many of these patients were reported on earlier, with manual perimetry studies." The present report includes findings obtained with automated perimetry only.

Our criteria for diagnosing LTG were: (1) a mean intraocular pressure of $21 \mathrm{~mm} \mathrm{Hg}$ or less; (2) glaucomatous optic disc cupping; (3) glauco- matous nerve fibre field loss; (4) open angle by gonioscopy; (5) absence of other ocular pathology.

Our patients were seen at three-monthly intervals. At each visit a mean of three intraocular pressure readings was obtained with the Goldmann tonometer. The anterior segments and optic discs were assessed by one of three glaucoma specialists and compared with the findings at previous visits. Humphrey automated perimetry using the central 30-2 program was also performed. Stereo optic disc photos were taken yearly. Visual fields were considered for analysis only if reliable. Reliability was defined ${ }^{12}$ by $(a)$ absence of fixation losses; (b) a false positive rate less than $20 \%$; $(c)$ a false negative rate less than $20 \% ;(d)$ constant stimulus and pupil size. The criterion of abnormality of fields was the presence of three contiguous points depressed by $>5$ decibels when compared with age matched normal persons within the central $30^{\circ} .{ }^{12}$

All analysed patients met the above criteria with respect to intraocular pressure, visual fields, and optic disc appearance. Patients whose mean intraocular pressure went over $21 \mathrm{~mm} \mathrm{Hg}$ during the follow-up period were excluded from the analysis. The same was true of those who developed significant lens opacities leading to poor visual testing performance.

Linear regression analysis was done on each tested retinal location in the Humphrey fields of each patient. At and from the third field onwards the sensitivity of each point in decibels was compared with that of the previous field. A slope showing a change in sensitivity of less than 0.2 decibel per month was considered to denote stability. On the other hand a slope showing a decrease in sensitivity of more than 0.2 decibel per month with a correlation coefficient of significance $\mathrm{p}<0.05$, was considered to denote progression (that is, worsening) in that specific point.

For the purpose of this analysis progression in a visual field was considered to have occurred if at least the last two consecutive slopes of one or more tested locations were negative $(p<0.05)$. All other possibilities, including a single negative regression slope, were considered to indicate a static field.
Results

Eighty four patients (168 eyes) met the study criteria. Fifty eight (69\%) were females, giving a female to male ratio of $3: 2$. This is no different 


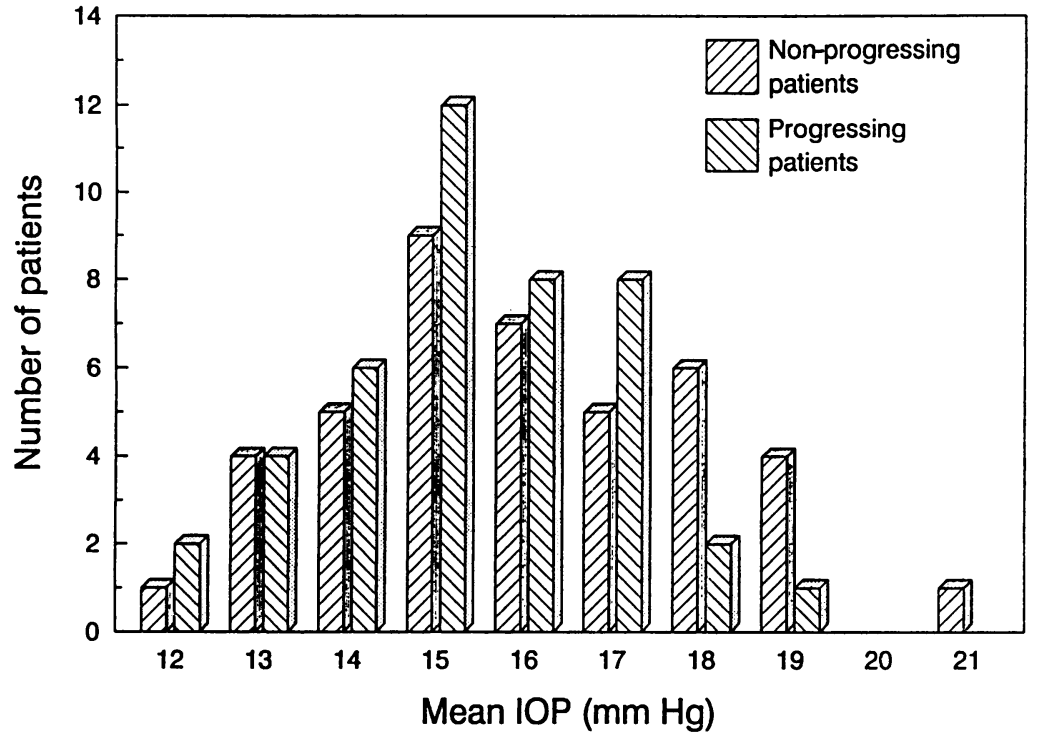

Figure 1 Distribution of patients according to their intraocular pressure means.

from that reported in previous series. ${ }^{71012}$ Their ages ranged from 38 to 86 years, mean 66 years. They all had in-hospital day phasing. Thirteen $(17 \%)$ of them had phasing repeated - once on presentation to the Glaucoma Unit at least six years before, and a second time more recently. Neurological disease was ruled out in every case. No patient was on any antiglaucoma treatment. A visual acuity of $6 / 12$ or better was present in each eye, and no lens opacities existed at the time of field testing.

The follow-up ranged from eight to 48 months, mean 28 months. Two-thirds of the patients had

Figure 2 Distribution of eyes according to their intraocular pressure means.

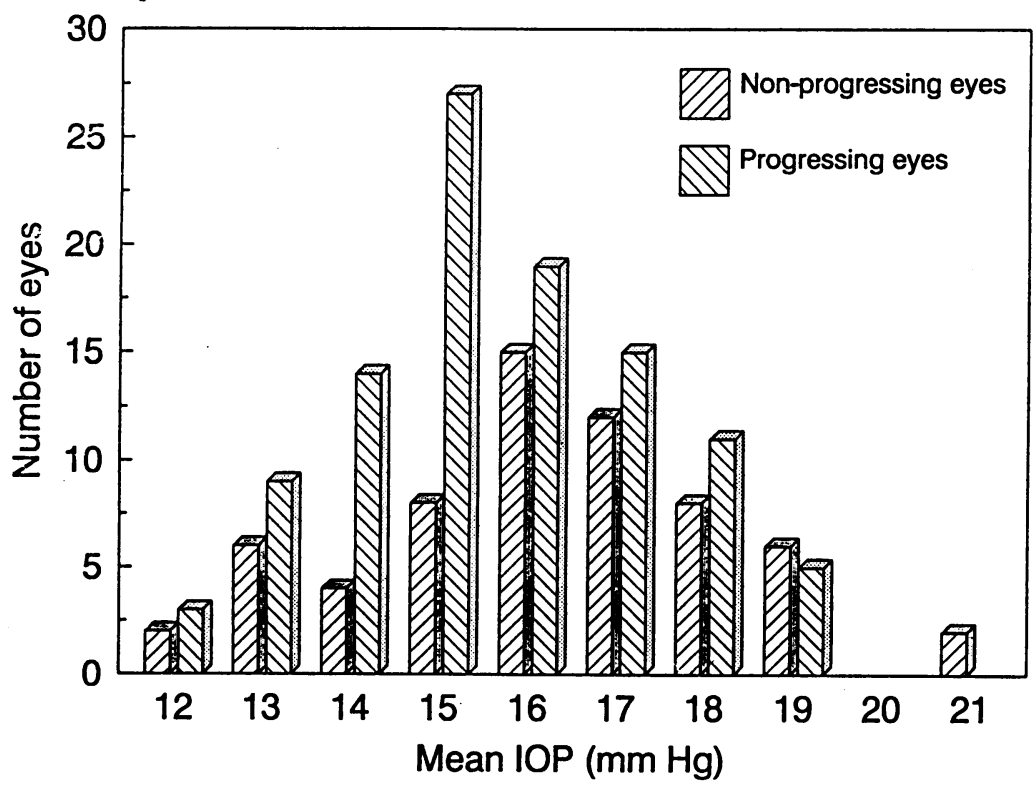

Table 1 Age and intra-ocular pressure (IOP) expressed as means, standard deviations (SD), and ranges in groups of patients and eyes

\begin{tabular}{|c|c|c|c|c|c|}
\hline & \multirow[b]{2}{*}{ Number (\%) } & \multicolumn{2}{|l|}{ Age in years } & \multicolumn{2}{|c|}{$I O P$ in $\mathrm{mm} \mathrm{Hg}$} \\
\hline & & $\operatorname{Mean}(S D)$ & Range & $\operatorname{Mean}(S D)$ & Range \\
\hline $\begin{array}{l}\text { Patients with non-progressing } \\
\text { eyes }\end{array}$ & $42(50 \%)$ & $65.78(10.03)$ & $38-86$ & $15 \cdot 60(1 \cdot 57)$ & $07-22$ \\
\hline $\begin{array}{l}\text { Patients with progressing eyes } \\
\text { Patients progressing in one eye } \\
\text { Patients progressing in both eyes } \\
\text { Non-progressing eyes } \\
\text { Progressing eyes }\end{array}$ & $\begin{array}{r}42(50 \%) \\
22(26 \%) \\
20(24 \%) \\
106(63 \%) \\
67(37 \%)\end{array}$ & $\begin{array}{l}66 \cdot 16(10 \cdot 21) \\
66.63(9 \cdot 84) \\
65.65(10 \cdot 58)\end{array}$ & $\begin{array}{l}47-85 \\
47-85 \\
48-84\end{array}$ & $\begin{array}{l}16.09(1.98) \\
15.97(2.21) \\
16.27(1.99) \\
15.66(1.73) \\
16.17(1.94)\end{array}$ & $\begin{array}{l}07-26 \\
07-22 \\
07-26 \\
07-24 \\
07-26\end{array}$ \\
\hline
\end{tabular}

years. The mean number of Humphrey fields per eye was eight, with a range of four to 14 . All but 10 patients had bilateral field defects, the rest had unilateral defects. They were included in the study as they satisfied all other criteria. The mean IOP was $16(15.98) \mathrm{mm} \mathrm{HG}$, range 7 to $26 \mathrm{~mm} \mathrm{Hg}$. (A single patient had one reading of $26 \mathrm{~mm} \mathrm{Hg}$; his mean intraocular pressure was $15.7 \mathrm{~mm} \mathrm{Hg}$ over 38 months.) The distribution of patients and eyes according to their IOP means is shown in Figs 1 and 2 respectively. Forty-two (50\%) patients and sixty-two (37\%) eyes were shown to have progressed. Among those patients who progressed $20(25 \%)$ did so in both eyes, while $22(26 \%)$ progressed in one eye only. Table 1 lists the mean age and mean IOP for patients and eyes.

Statistical analysis by comparison of the means showed that there was no statistically significant difference between progressing and non-progressing patients with respect to age $(\mathrm{p}<0.5)$ or IOP $(p<0.5)$. The same was true between patients showing progression in one eye and those showing progression in both $(\mathrm{p}<0.5)$. Progressing and non-progressing eyes showed no significant difference in their IOP $(p<0 \cdot 5)$. The mean follow-up was 28 months for patients with both progressing and non-progressing eyes.

Table 2 shows the detailed location of the field defects: (a) altitudinal (superior and inferior); $(b)$ advanced loss $\left(360^{\circ}\right) ;(c)$ paracentral (within $10^{\circ}$ of fixation); (d) quadrantic (supero- or inferonasal, supero- or inferotemporal); (e) vertical (nasal or temporal). Fig 3 shows the same by restricting the analysis to the superior and inferior hemifields and to advanced and paracentral loss.

\section{Discussion}

Linear regression analysis gave negative regression slopes significant at the 0.05 level in $50 \%$ of patients (37\% of eyes). These figures compare well with these reported by Chumbley and Brubaker, ${ }^{9}$ Levene, ${ }^{10}$ and Anderton et a $l^{11}$ using manual perimetry. They are lower than the $53 \%$ and $62 \%$ reported by Glicklich $e t a l^{12}$ at three and five years of follow-up respectively with computer assisted perimetry. One reason for the difference between our results and those of Glicklich et al is that we included as 'progression' only those eyes with evidence of continued progression on repeat testing three to six months later.

Compared with cases of high pressure glaucoma, cases of LTG scotoma were found to be closer to fixation, ${ }^{24610}$ and to be deeper and to have steeper slopes by some authors ${ }^{24}$ but not by others. ${ }^{6}$ However, all published material agrees that the superior hemifield ${ }^{3411}$ and specifically the superonasal quadrant ${ }^{12}$ are the most frequent locations for LTG defects. Our analysis (Table 2) also shows the superior hemifield to be mostly affected in both non-progressing and progressing eyes ( $40 \%$ and $52 \%$ respectively). Advanced loss $\left(360^{\circ}\right)$ was found in $21 \%$ and $18 \%$ respectively. This comes as no surprise. Being asymptomatic in terms of IOP, LTG patients are discovered late in the course of their disease. A number of eyes (4\% of non-progressing and $13 \%$ 

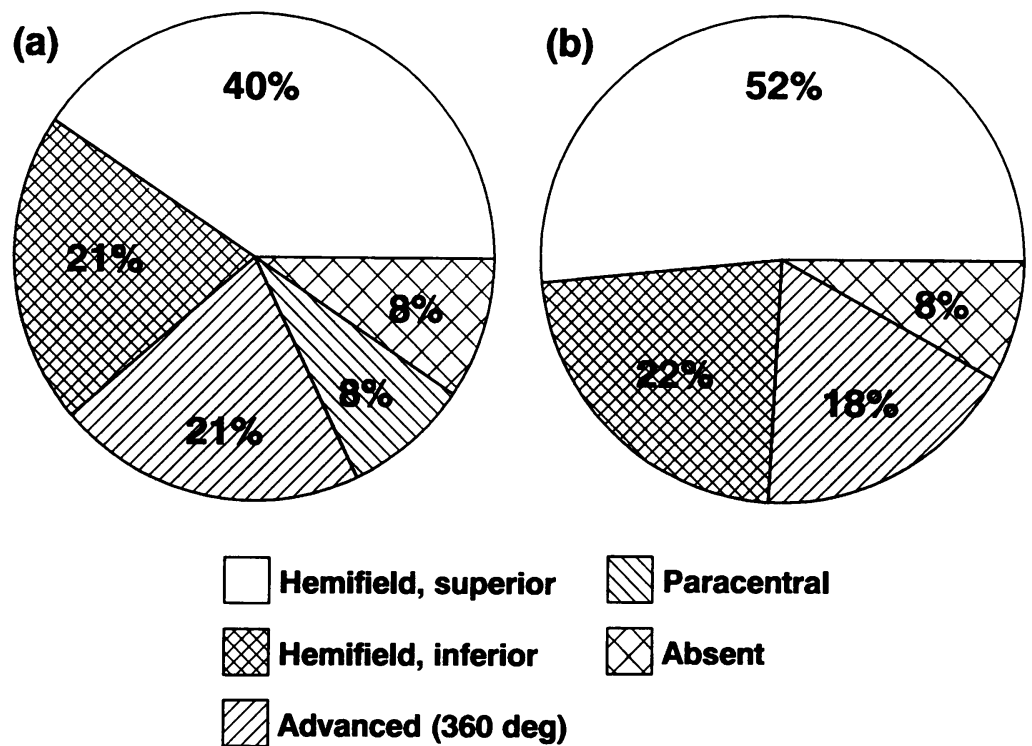

Figure 3 Location of field defects in (a) non-progressing and $(b)$ progressing eyes.
Table 2 Detailed location of field defects in non-progressing and progressing eyes

\begin{tabular}{|c|c|c|c|c|}
\hline \multirow[b]{2}{*}{ Location of defect } & \multicolumn{2}{|c|}{ Non-progressing eyes } & \multicolumn{2}{|c|}{ Progressing eyes } \\
\hline & No. & $(\%)$ & No. & $(\%)$ \\
\hline \multicolumn{5}{|l|}{ Altitudinal } \\
\hline Superior & 18 & $(17 \%)$ & 13 & $(21 \%)$ \\
\hline Inferior & 4 & $((4 \%)$ & 5 & $(8 \%)$ \\
\hline Advanced $\left(360^{\circ}\right.$ loss $)$ & 22 & $(21 \%)$ & 11 & $(18 \%)$ \\
\hline Paracentral & 9 & $(8 \%)$ & 5 & $(8 \%)$ \\
\hline \multicolumn{5}{|l|}{ Quadrantic } \\
\hline Superonasal & 22 & $\begin{array}{l}(21 \%) \\
(11 \%)\end{array}$ & $\begin{array}{r}13 \\
3\end{array}$ & $\begin{array}{r}(21 \%) \\
(5 \%)\end{array}$ \\
\hline $\begin{array}{l}\text { Inferonasal } \\
\text { Superotemporal }\end{array}$ & $\begin{array}{r}12 \\
1\end{array}$ & $\begin{array}{r}(11 \%) \\
(1 \%)\end{array}$ & $\begin{array}{l}3 \\
2\end{array}$ & $\begin{array}{l}(5 \%) \\
(3 \%)\end{array}$ \\
\hline Inferotemporal & 4 & $(4 \%)$ & 2 & $(3 \%)$ \\
\hline \multicolumn{5}{|l|}{ Vertical } \\
\hline Nasal & 1 & $(1 \%)$ & 2 & $(3 \%)$ \\
\hline Temporal & 3 & $(3 \%)$ & 6 & $(10 \%)$ \\
\hline Absent defect & 10 & $(9 \%)$ & 0 & $(0 \%)$ \\
\hline
\end{tabular}

occurring, and that the mean interval between periods of progression was $4 \cdot 4$ years.

In the absence of any tested alternative for the treatment of low tension glaucoma it is important to assess the hyopthesis that progressive visual loss in this disease occurs because the IOP is too high for the eye and to run a trial of treatment versus no treatment. Such studies are now under way.

1 Von Graefe A. Uber die Ridectomie bei Glaucom und über den glaucomatosen Prozess. Graefes Arch Clin Exp Ophthalmo 1857; 3: 456-650.

2 Hitchings RA, Anderton SA. A comparative study of visual field defects seen in patients with low tension glaucoma and chronic simple glaucoma. Br f Ophthalmol 1983; 67:818-21.

3 Motolko M, Drance SM, Douglas GR. Visual field defects in low tension glaucoma. Comparison of defects in low tension glaucoma and chronic open angle glaucoma. Arch Ophthalmol 1982; 100: 1074-7.

4 Caprioli J, Spaeth GL. Comparison of visual defects in low tension glaucoma with those in high tension glaucoma. Am F Ophthalmol 1984; 97: 730-7.

5 Lewis RA, Hayreh SS, Phelps CD. Optic disc and visual field correlations in primary open angle glaucoma and low tension glaucoma. Am $\mathcal{F}$ Ophthalmol 1983; 96: 148-52.

6 King D, Drance SM, Douglas G, Schulzer M, Wigsman K. Comparison of visual field defects in normal tension glaucoma and high tension glaucoma. Am $\mathcal{F}$ Ophthalmol 1986; 101: 204-7.

7 Drance SM, Douglas GR, Airaksinen PJ, Schulzer M, Hitchings RA. Diffuse visual field loss in chronic open angle and low tension glaucoma. Am f Ophthalmol 1987; 104: and low

8 Chautian BC, Drance SM, Douglas GR, Johnson CA. Visual field damage in normal tension and high tension glaucoma Am F Ophthalmol 1989; 108: 636-42.

9 Chumbley LC, Brubaker RF. Low tension glaucoma Am $\mathcal{F}$ Ophthalmol 1976; 81: 761-5.

10 Levene RZ. Low tension glaucoma: a critical review and new material. Surv Ophthalmol 1980; 24: 621-41.

11 Anderton SA, Coakes RC, Poinoosswamy S, Clarke P, Hitchings RA. The nature of visual loss in low tension glaucoma. In: Heiil A, Greve E, eds. Doc Ophthalmol Proc Ser 42. 6th International Visual Field Symposiumol Proc Margherita, Ligure. Amsterdam: Junk, 1984: 383-6.

12 Gliklich RE, Steinmam WC, Spaeth GL. Visual field change in low tension glaucoma over a five year follow up. low tension glaucoma over
Ophthalmology 1989;96: 316-20.

13 Bloomfield $S$. The results of surgery in low tension glaucoma. Am $\mathcal{f}$ Ophthalmol 1953; 36: 1067-70.

14 Hitchings RA. Low tension glaucoma. Is treatment worthwhile? Eye 1988; 2: 636-40.

15 de Jong N, Greve EL, Hoying PFJ, Geijissen HC. Results of filtering procedure in low tension glaucoma. Int Ophthalmo 1989; 13: 131-8. 